\title{
Self-Build and Custom Housebuilding Registers in England: A Transaction-Cost and Effectiveness Analysis
}

\author{
Grace Sadler ${ }^{1}$ and Sina Shahab ${ }^{2, *(D)}$ \\ 1 St. Modwen Homes, Birmingham B31 2UQ, UK; GSadler@stmodwen.co.uk \\ 2 School of Geography and Planning, Cardiff University, Cardiff CF10 3WA, UK \\ * Correspondence: shahabs@cardiff.ac.uk; Tel.: +44-(0)29-2087-6092
}

Citation: Sadler, G.; Shahab, S.

Self-Build and Custom

Housebuilding Registers in England:

A Transaction-Cost and Effectiveness

Analysis. Sustainability 2021, 13, 4912.

https://doi.org/10.3390/su13094912

Academic Editor: Masa Noguchi

Received: 30 March 2021

Accepted: 25 April 2021

Published: 27 April 2021

Publisher's Note: MDPI stays neutral with regard to jurisdictional claims in published maps and institutional affiliations.

Copyright: (c) 2021 by the authors. Licensee MDPI, Basel, Switzerland. This article is an open access article distributed under the terms and conditions of the Creative Commons Attribution (CC BY) license (https:// creativecommons.org/licenses/by/ $4.0 /)$.

\begin{abstract}
The development of the self and custom housebuilding sector can work towards increasing the supply of housing and alleviate some of the strain on the housing market in England. Although it is not a solution for everyone, improving self and custom housebuilding can add diversity to the market, increase housing affordability, and produce sustainable homes. This has been recognised by the UK Government, which has introduced legislation which aims to assist self and custom builders on the journey to building their own home. The goals of the legislation are to ensure every local authority in England keeps a register of individuals who want to build their own home, to consider this register when carrying out other planning functions, and to grant sufficient planning permissions for those on the register. This paper evaluates the 'self-build and custom housebuilding registers' from the perspective of transaction costs and perceived effectiveness. This is achieved through semi-structured interviews with local authority planners, private-sector planners, property developers, and national bodies. The findings of this study identify that the primary transaction costs occur in the eligibility tests stage of the register application and relate to the uncertainty felt by applicants post application. The paper concludes that these could be rectified by implementing a more consistent and fair system. The perceived effectiveness of the register varies considerably. The paper determines that the policy requires significant change in order to meet the goals it set out to achieve, which includes model Supplementary Planning Guidance documents and a robust support system for applicants.
\end{abstract}

Keywords: self-build and custom housebuilding; housing; development management; policy analysis; transaction costs; effectiveness

\section{Introduction}

The UK housing market is in crisis. One of the reasons for this crisis is rooted within the under supply of housing [1-3]. The issue of under supply of housing in the UK was brought back to the forefront of policy following the Barker Review in 2004 [4]. The general consensus is that the UK needs to build 225,000 to 275,000 new homes each year, to catch up with years of under-supply and meet the needs of a growing population [5-7]. Since 1990s, the country has entered a period of demographic change, where more new households are formed each year, which has intensified shortfalls in supply of housing [8]. For instance, the number of households increased by $0.9 \%$ from 2018 to 2019, resulting in a total of 27.8 million households in the UK [9]. As the number of households continue to grow each year, the pressures on housing supply increase, and significant amounts of new homes need to be built each year to account for the increased and existing need for suitable housing [10].

It is evident that the homebuilding sector in the UK is dominated by the largest companies, as the eight largest companies build more than half of all new homes [10]. Over the last 30 years, small and medium housebuilders have struggled to become established and grow due to economic recessions and challenging policy conditions, whilst large housebuilders have continually dominated the market [11]. This domination has resulted 
in a homogeneous market controlled by volume homebuilders [12]. Therefore, to meet housing demand, the government has concluded that the market must become more competitive and more diverse $[10,13]$. The government has suggested a multitude of ways this could be achieved, which are mostly based around planning, to ensure planning rules set out specific guidelines relating to diversity and provide incentives to diversify the market [13]. One way includes promoting and supporting self-build and custom housebuilding as a pathway for people to plan and build their homes and provide much needed diversity to the housing market.

Self-build and custom housebuilding dwellings as a percentage of national housing completions in England have historically been very low compared to most developed countries [14-16]. Only $7-10 \%$ of new builds are produced through self and custom build [17], despite the fact that $53 \%$ of people would consider building their own home [18]. This illustrates a major discrepancy between supply and demand. The main barriers selfbuilders face include access to finance, land supply, the planning process/regulations and lack of information $[17,18]$. To try and eradicate these barriers the UK Government has produced policy and legislation to aid self and custom builders, most notably, Self-build and Custom Housebuilding Act (2015), The Right to Build (2015), and the Housing and Planning Act (2016). One of the main outcomes of these policies and legislations is that, since 2015, every local authority in England has been required to keep a register of individuals or associations who wish to complete self or custom housebuilding projects [16]. Furthermore, each authority is required to consider this register when carrying out other planning functions and grant sufficient planning permissions. Through this, the government hopes to support the sector and the large number of people hoping to build their own home [6]. Although research has been conducted into the sector by National Custom and Self Build Association (NaCSBA), this mainly uses statistical data to investigate how the self-build registers are being used in each local authority (see NaCSBA, 2020). However, there are no current evaluations of self-build register policy in England, which use underpinning theories to draw valid conclusions. Therefore, this research seeks to address if the register and associated policies are achieving the goals they set out to achieve.

This paper uses two criteria of transaction costs and perceived effectiveness to evaluate self-build register policy in England. Transaction costs are all the costs involved in exchanges or transactions, other than production costs [19], and they influence efficiency and equity of public policies [20,21]. Analysing such costs enables decision makers to determine what elements of the register process are successful and what challenges applicants and local authorities face. Perceived effectiveness is concerned with how well the parties involved with the policy perceive that it is meeting the goals and objectives it set out to achieve [22]. Self and custom build policy has not been qualitatively evaluated thus far; therefore, this research works towards using underpinning theories and criteria to assess the policy and make recommendations to reduce transaction costs and increase effectiveness.

The overarching aim of this research is to evaluate the transaction costs associated with and the perceived effectiveness of the self-build register, according to involved parties. To this end, three research questions are formulated and addressed: RQ1: What transaction costs are associated with the application process to the self-build register? RQ2: How do parties involved with the self-build register perceive the effectiveness of the policy? RQ3: What are the ways to reduce transaction costs and improve the effectiveness of self-build register policy in England? The paper is structured as follows. Firstly, it critically reviews literature and policy relating to self and custom housebuilding and how transaction-cost theory and perceived effectiveness can be used to evaluate policy. This section highlights the gap in the literature that this research seeks to address. This is followed by the methodology section which discusses the research methods used in the research. Next, the data collected is set out in the findings and analysis section, where each research question is addressed in turn to determine the findings and make links back to the literature and policy. 
The final section presents the conclusions for each research question, whilst providing policy recommendations.

\section{Literature Review}

\subsection{Self and Custom Housebuilding}

\subsubsection{Definition}

Self-building can be broadly defined as any form of housing where the first occupants are involved its construction, this can range from organising the construction to building it themselves [5,16]. Benson [23] suggests that the variation of routes that can be taken to produce a self or custom build home should all fall under the umbrella term of 'self-build'. Whereas Parvin, et al. [24] use the term 'self-provided' to describe the process of those who will be living in the dwellings taking responsibility for the procurement of their own home.

Although often coined together, 'self-build' and 'custom-build' housing do have distinctions [25]. The UK National Custom and Self Build Association (NaCSBA) define them as follows. Self-build refers to projects that are directly organised, designed, and constructed by the person and/or group who are constructing it [18]. This definition encompasses a range of projects, including the traditional 'DIY (do-it-yourself) home' where the self-builder would complete the design and construction work themselves. It also includes self-build projects where the builder receives some help, whether in the form of the assistance of an architect/contractor or if they use a kit home company. Additionally, many community-led projects are often considered to be self-build as the group is responsible for much of the work. In sum, self-build homes are defined here as when "people roll their sleeves up and get their hands dirty by organising or doing the physical work themselves" (Wilson, 2017:4). Custom-build on the other hand is a less hands-on approach, as here NaCSBA suggest that builders are likely to work with specialist developers, who will ease some of stresses of building your own home. This has resulted in the expansion of custom-build developers, who can have varied degrees of involvement in the project. Wilson [18] notes that custom-build developers often provide a 'menu of custom build options', ranging from only providing a serviced plot, building the home to a watertight stage, or completing the entire construction.

\subsubsection{Self and Custom Housebuilding in the UK}

The UK is significantly behind the rest of Europe in terms of the self and custom build market. Data obtained by NaCSBA in 2011 indicated that as little as 7-10\% of new builds in the UK are produced through self and custom build, whilst in France it is 38\%, Germany is $60 \%$, and Austria up to $80 \%$ [26]. There is some evidence to suggest that the demand for self and custom building in the UK is much higher than the supply suggests [18]. A 2011 survey commissioned by the Building Societies Association (BSA) determined that $53 \%$ of people in the UK would consider a build-your-own-home project, if they had the opportunity [18]. However, NaCSBA identified that the number of completions is growing year-on-year, as 13,210 projects were completed in the 2018-19 financial year, which is a $2.2 \%$ increase on the previous year [27]. Overall, it seems that the demand for self and custom housing is not being met in the UK, but it can be difficult to accurately state the level of self-build activity as no official data on procurement route are collected [5].

The UK Government policy initiatives regarding self and custom build began to gain traction from 2011, through a Government-Industry Working Group who produced an Action Plan to promote the growth of self-building housing [18]. The Action Plan set out a Vision Statement which highlighted the aspirations of the group to "facilitate the doubling of the number of self-build homes built annually over the next decade, and to enable a new generation of younger self builders to deliver their own affordable homes" (NaCSBA, 2011, p. 2). Further stating that this will be achieved through working with the government to eradicate the key barriers to self and custom build, which include access to finance, land supply, the planning process/regulations, and lack of information [17,18]. An important development in this regard was the Self-build and Custom Housebuilding 
Act (referred to as 'The Act' in this paper), which was published in 2015. The Act places a statutory duty on authorities to keep a register of individuals or associations who wish to complete self or custom housebuilding projects, this is now referred to as 'self-build register'. Each authority has a duty to take the self-build register into consideration when carrying out their functions in relation to housing, planning, land disposal and regeneration [18]. The government has also issued online guidance to the authorities on what should be included in the self-build register and how it should be maintained, this includes applicant eligibility. The website details that relevant authorities could set 'local connection tests' as part of their registers, if they chose to do this, their register should be completed in two parts. Part 1 includes applicants who meet all the eligibility criteria and Part 2 includes applicants who meet all criteria, excluding the local connection test [28]. The guidance includes further details stating that authorities should be publicising their self-build registers through designated sections on their website and requesting optional additional information regarding plot location and size [28].

Although the self-build registers have been active for nearly five years with the overarching aim to facilitate self and custom build housing, how do we know if the register is achieving its goals? NaCSBA [29] and Gingell and Shahab [16] have recently published research which use Freedom of Information requests to analyse the activities of local authorities around the self-build register. They show that local authority activity is largely concerned with managing the registers down rather than managing delivery up, as they have been found to limit new entries onto registers and remove existing entries [29]. It is evident that existing research have been concerned with the status of the self-build registers, but there are currently no evaluations of them. Moreover, there is no research which considers the general process of the register and the barriers or obstacles applicants may face. Consequently, this research aims to evaluate the self-build register through the lens of transaction costs and perceived effectiveness.

\subsection{Policy Analysis and Evaluation Criteria}

For planning evaluation to be successful it should be systematic and use explicit criteria or indicators to assess plans, processes, and outcomes [30]. As without this, the judgement planners make regarding if a plan or policy is good or not, cannot be justified or validated [31]. In this research, we use two evaluation criteria of transaction costs and perceived effectiveness to evaluate self-build register policy in England.

\subsubsection{Transaction Costs}

Transaction costs are the costs involved in exchanges or transactions, other than production costs [32]. The origins of transaction-cost theory stems from New Institutional Economics, where the concept was initially developed by Coase [33] as the cost of using the price mechanism. The concept emerged as an attempt to explain factors that had been traditionally overlooked in classical economics, which presumed a perfect market [34]. In transaction-cost theory, the basic unit of analysis is the transaction [35], which includes any exchange between different parties, from simply exchanging goods and services for payment to more complex exchanges of information [36]. The three most common dimensions of transaction costs are referred to as asset specificity, uncertainty, and frequency [37,38]. Asset specificity refers to whether an asset which is used to support a transaction can be redeployed to a higher valued use [39]. As asset specificity increases, so does transaction costs. Uncertainty links to 'information impactedness' where there is limited and/or asymmetric information regarding a transaction, which increases transaction costs. Finally, frequency refers to the number of times the transaction is expected to take place, where independent and frequent transactions result in lower transaction costs than infrequent, long-lasting transactions [19].

McCann, et al. [40] emphasise the importance of considering transaction costs in policy choice and design, as they can affect the efficiency and effectiveness of policy instruments. Buitelaar [41] states that transaction-cost theory can be used as an analytical tool in planning 
to investigate and compare institutional arrangements in theory and practice. Research has shown that if there are high transaction costs involved with implementing a policy, this will decrease the policy efficiency as they are 'dead weight losses' which should be minimised [42]. According to Shahab and Lades [43], such losses can occur when a party spends too much time and effort to receive a service or good. Furthermore, it is likely that the transaction costs which occur when implementing a policy are unevenly distributed among involved parties, which results in inequitable outcomes [44]. By using transaction-cost theory to evaluate planning policy, we can identify where such costs occur and why they are generated and distributed. This would allow policy makers to reduce or redistribute transaction costs to contribute to better land use decisions [41].

\subsubsection{Perceived Effectiveness}

Effectiveness can be defined as the degree to which a policy instrument achieves the goals or objectives it was expected to achieve [31]. It can further be defined as how well a policy instrument works or whether it works as intended and meets the purposes for which it is designed [45,46]. Assessing the outcomes of policy instruments is especially important in the planning system, as the system can be seen as a burden to developers, it is crucial to understand when policy is successful or failing [47]. One way in which effectiveness can be assessed is through perceptions, which can be defined as the way in which an "individual observes, understands, interprets, and evaluates a referent object, action, experience, individual, policy, or outcome" (Bennett, 2016, p.585). When linked back to effectiveness, the perceived effectiveness of a policy refers to an individual's positive or negative perception of that policy instrument [48]. It is proposed that when a policy instrument is perceived to be more effective this results in a higher level of intention to carry out that behaviour [49]. Lubell, et al. [50] build on this by stating that a participant's perception will depend on the contribution of the policy towards the collective good but also their individual gains and losses. Perceived effectiveness has frequently been used for evaluating policy outcomes. Wan, Shen and Yu [48] considered perceived policy effectiveness in regard to recycling behaviour. Greiner and Gregg [51] considered how perceived effectiveness affected farmers' adoption of conservation practices. However, the perceived effectiveness of self-build register policy among the relevant parties in England has not been explored.

\section{Methodology}

The aim of this research is to evaluate the self-build register policy in England in relation to transaction cost and perceived effectiveness. The research determines what transaction costs occur when applying to the self-build register, who they are incurred by, and how they can be mitigated. Then, it explores how effective the policy is perceived to be by different parties who are involved with or implicated by it. This enables the researchers to make recommendations to reduce transaction costs and improve the policy effectiveness. The primary method of data collection for this research was semi-structured interviews. The flexibility offered by this data collection method enabled the researchers to address specific dimensions of the research, whilst leaving space for the participants to offer new thoughts and opinions [52].

A total of 21 participants were interviewed in order to reach data saturation, whereby no further insights were being generated from data collection [53]. The participants included nine public-sector planners involved in the register, five private-sector planners, three custom-build developers, two planning professionals in charitable organisations, and two academic researchers. Interviews lasted for a time ranging from 30 to $60 \mathrm{~min}$. The interviews were carried out largely through telephone or online via Zoom between July and October 2020, when due to the ongoing COVID-19 pandemic, in-person interviews were not possible. In order to explore the participants perceptions, open ended questions were used to encourage them to expound on the topic and avoid short answers [54]. The questions included asking the participant to break down the application process of the 
self-build register into stages, discussing the time-consuming features of the process, and asking how well they think the register achieves its goals.

All interview responses were recorded with the prior consent of the participants and anonymously transcribed. The transcriptions were then analysed using thematic analysis. Thematic analysis is suitable for this study as it is a useful method for understanding the perspective of different interview participants and emphasising the similarities and differences within their responses [55]. To ensure the research questions were fully addressed through the thematic analysis, each question was analysed in turn. The data collected from the interviews was grouped into themes under each research question. For example, research question two involved the analysis of two policy objectives so we began by collating all the relevant information from the interviews for each objective. We then identified themes and patterns in the data. This allowed the researchers to structure the analysis around key themes and the corresponding interview quotes. After the interview data was structured into a coherent argument, links were established between the analysis and literature review to solidify the arguments.

\section{Results and Discussions}

\subsection{Transaction Costs Associated with the Self-Build Registers}

The process of applying to the self-build register involves a few activities for the applicant and the associated local authority. Although it is not a lengthy process, the applicant is still likely to face a number of transaction costs when applying to the register. This section aims to determine when the transaction costs occur and who incurs the costs. Each interviewee was asked to explain, in detail, the process of applying to the self-build register from the perspective of an applicant. From this, each stage of the process has been identified as follows. The first stage is identified as applying to the register through an online application process, this is often followed by an eligibility tests to determine if the applicant has a strong connection to the area. This process can also involve a fee that must be paid to be added to the register. Once this application has been made, the next stage sits with the local authority to utilise the applicant's information. The information obtained from the interviews is summarised in Table 1, showing the category of activities, examples of transaction costs and who they are incurred by.

Table 1. Transactions associated with self-build register application, the related transaction costs, and parties involved.

\begin{tabular}{ccc}
\hline Category of Activities & Examples of Transactions Creating Transaction Costs & Main Parties Involved \\
\hline & Finding the relevant information on the local authority's website & Applicant \\
Applying to the register & Entering personal information of individual or association & Applicant \\
& Entering information regarding size and location of land plot (not & Applicant \\
& always mandatory) & Applicant, Local Authority \\
Eligibility tests & Local connection test & Applicant, Local Authority \\
Post application & Local Authority & Updates from the local authority \\
\hline
\end{tabular}

The first step in applying to the self-build register involves the completion of an application form and returning it to the relevant local authority. Although the application form was described as "clear and concise" and "relatively simple" by several local authority planners, there are still some small transaction costs that the applicant can face when applying. First, each applicant must find the relevant page of the local authority's website, this may seem like a straightforward task but often the registers are not publicised at all. Two local authority planners who were interviewed emphasised the lack of publicisation in their councils, one stated that, "it [the register] is not advertised to the full extent, it is up there because we have to do it". Another planner commented that their register should be promoted in more diverse ways as they have a young demographic that apply, so the council could utilise social media to reach more potential applicants, as "it is not enough to just have a page on the website". The lack of publicisation of the register was linked to local authorities being cautious to promote their registers, as a NaCSBA interviewee 
noted, if they do promote, they are worried they will have too many applicants and be unable to fulfil their duties. One interviewed local authority described publicising the register as "making a rod for your own back" as with more people on the register, they are required to grant sufficient planning permissions, according to The Act. Furthermore, they highlighted the lack of resources available to monitor and implement the register, meaning more applicants would increase the already struggling workload. However, this has resulted in obstructions to the initial application process as applicants may struggle to find the appropriate place to apply if the application page is not publicised or clearly visible.

After the applicant has obtained the application form, the process of completing it is mostly straightforward. As briefly mentioned, every local authority planner that was interviewed stated that the application form is clear, comprehensive, and easy to complete. All application forms involve entering the personal information of the individual or association applying to the register. Most applications require the applicant to submit additional information regarding preferred location, size of plot, and how they plan to finance the build. This information is then used within the authority to inform policy and planning decisions, it is deemed necessary and useful by local authority planners. However, one developer suggests that requiring additional information from applicants can hinder the process, as many people "will not have a firm idea of budget and number of bedrooms when first entering". The developer continued to explain that inflexible registers that 'pigeon-hole people's requirements' are likely to obstruct applicants and discourage those who may not have the additional information required.

The next stage of the application process involves eligibility tests which are set by each local authority. The scope of these tests vary, as some authorities do not impose any restriction on joining the register and others use local connection tests and/or charges. Information obtained by NaCSBA indicates that $31 \%$ of councils now impose some sort of restriction, with $30 \%$ using local connection tests and 15\% using a charge (NaCSBA, 2020). Evidently, the restrictions are not evenly distributed amongst individuals, results in an inequitable process [32]. When discussing the local connection tests with authorities that do enforce it, it was clear that the applicant would incur costs. As they are required to prove beyond doubt to the local authority that they have a suitable connection to the area, often through residency or employment-based connections. For instance, an applicant seeking to pass the local connection test is required to "dig out paperwork/utility bills etc. from more than three years ago" to submit alongside their application. This process creates transaction costs for the applicant, as it may be time consuming or difficult to find the relevant information, which could lead to people abandoning the process if they cannot obtain the documents they need. Furthermore, it has been questioned if local connection tests are entirely necessary for the register, as a self and custom build developer highlights, the tests remove the potential for people to migrate within the country to live or work, which they argue is "completely at odds with 21st century living and working patterns". Therefore, the transaction costs associated with proving you are eligible to be on a register, which can obstruct and deter applicants, may be unnecessary and avoidable.

In addition to local connection tests, local authorities can charge a registration fee to applicants who would like to be added to their register. This was introduced in 2017 by the government, and it clearly states that the fee should only be set on a cost recovery basis and should reflect the genuine costs incurred by the authority [28]. However, during the interview with a NaCSBA representative, it was clear that this was not the case for some local authorities. The interviewee explained that most fees are much higher than the cost of the amount of work it takes to process an application, one example cost over GBP 700 to be on the register since it has been in progress. The registration fee is evidently the largest transaction costs in the application process of the self-build register, as facing such fees upwards just to register is likely to deter many people and pose a significant barrier to applicants. Furthermore, many applicants may not be able to afford excessive fees which result in little return. 
The final stage of the process follows the submission of an application, where the applicant should be contacted by the local authority. From the interviews, it is clear that this contact is brief and essentially a confirmation of being added to the register. The interviewed local authority planners stated that they receive the most queries from applicants regarding this stage of the process. The queries are often related to the next steps once they have applied to the register and the misconceptions surrounding the role of the council. One local authority planner explained a common exchange here:

"I have 10 emails from people asking, so what happens now after they have signed up to the register and you have to politely say well the council has done everything that they are legally required to do. So, there is a big issue that applicants are expecting more from being on the register because it is not clear what happens next."

There is a level of uncertainty for applicants, as they are not clear what happens post application and many expect more help or information from the local authority. This uncertainty is caused by misconceptions of the registers purpose, as it is primarily used to measure demand, but interviewees note that applicants are expecting the authority to find or allocate them a plot. As Alexander [36] notes, limited or unclear information regarding a transaction will increase transaction costs, which is evident here. Furthermore, the 'information impactedness' is negatively affected due to the limited information, resulting in increased transaction costs [56]. In this case, the transaction costs are incurred by the applicant and the local authority, as the applicant faces uncertainty whilst the local authority is required to spend time clarifying the misconceptions.

\subsection{Perceived Effectiveness of the Self-Build Registers}

4.2.1. Perceived Effectiveness of Objective One: Increasing the Number of Self or Custom Build Homes in England

The first objective of the policy is to increase the number of self or custom build homes in England. It aims to achieve this by building on previous government initiatives and raising awareness of the sector, measuring demand, and providing more support for people who want to build their own homes. As this objective is not clearly set out in The Act, it has been determined primarily through analysis of the semi-structured interviews, when interviewees were asked if they thought the register supported people wanting to build their own home. This question was derived from Self and Custom Housing Briefing Paper [18] and the Right to Build: Supporting Custom and Self Build-Government response to consultation [6], where it is clearly outlined how the government are determined to support the custom and self-build sector. Therefore, data collected through the semistructured interviews and analysis of government documents relating to The Act has informed this objective. The following discusses how effective the policy is perceived to be at achieving this objective, from the perspective of key actors.

Overall, the perceived effectiveness of this objective varies between and within the different parties that were interviewed. This links to Bennett's conclusion that as we all have unique experiences and motivations, unlike and even like groups can perceive the same policy very differently. Public-sector planners, private-sector planners, developers, and NaCSBA all agreed that in terms of increasing awareness of the self and custom build market, the policy has been effective. An interviewed private-sector planner noted that the register has made a distinct improvement to where the sector was 10 years ago. Similarly, NaCSBA stated that the register has greatly influenced awareness, as "every single local authority is now aware of custom and self-build", when this was not the case before the register.

However, the perceptions of different parties start to vary when discussing if the register is a useful tool to measure demand. Three local authority interviewees noted that the register is beneficial to monitor the demand for self and custom build in their authority and provides a mechanism for the demand to be recorded. However, the NaCSBA representative and three other local authority planners question the validity of the measured 
demand. This is due to the difficulties in measuring the sector, as there is no robust method to counting what houses qualify as self or custom build. As CIL exemptions can be used, but not all areas enforce CIL charges, resulting in inconsistent data. Furthermore, managing the registers can be challenging as local authority planners believe many people stay on the registers 'just in case' and have no real intent to build their own home. Moreover, an applicant can join as many registers as they wish in different authorities, which can result in double counting and skewed data. These factors contribute to the policy being perceived as ineffective at measuring demand of the sector and evidently some improvements could be made to clarify the process.

In terms of supporting people who desire to build their own home, it is evident from the interviews that this is not being achieved through the self-build register. Most interviewees expressed their concerns that the register does not go beyond measuring demand. One public-sector planner stated that "it seems like a tick box exercise as I cannot help people after they have applied". Although councils are fulfilling their legal duties by solely keeping the registers, there is a common misconception by applicants that the purpose of the register is for authority to find them a suitable plot to build on and further support the process. As this is not the case, applicants are often left disappointed with the lack of support. The local authority planners noted that they would like to assist applicants further but the registers are often not their top priority, or they do not have the resources. This results in an unsatisfactory experience with the self-build register, which in line with Wan, Shen and Yu [48], is likely to decrease the perceived effectiveness.

4.2.2. Perceived Effectiveness of Objective Two: Taking Account of the Demand for Self or Custom Build Homes by Local Authorities When Making Plans and Policies

The second objective set out in The Act is that councils must consider the demand on the self-build register when carrying out their other functions in relation to housing, planning, land disposal, and regeneration. This objective is not very detailed in The Act, it simply states that each council should take regard of the register when carrying out the functions. Morrison and Pearce [47] highlighted the difficultly in measuring the effectiveness of policy instruments when they lack clear language or detail.

The interviews have shown that there is an overall disparity in the perceived effectiveness of this objective between the parties in control of the registers (i.e., local authorities) and the other parties the register should be supporting (e.g., developers and NaCSBA). As eight out of nine of the local authority planners interviewed stated that the information collected through their register was being used within the authority when carrying out other functions, suggesting the policy was perceived as effective. The interviewees highlighted how the register is being used to inform decision making in their authority. Examples of this include, reviewing the Draft Local Development Plan to include a policy where sites of 20 plots or more are expected to provide 5\% of plots for serviced self or custom build. Similarly, another Draft Local Plan is looking to support the sector by encouraging developers to include $10 \%$ of dwellings as available serviced plots on sites of 10 or more dwellings, where there is an identified need on the register. In one authority, the Planning Inspector has inserted a policy requirement for developers to provide self-build plots on new Sustainable Urban Extensions (SUEs). However, each of these policy changes come with their own challenges. The Draft Local Plan changes have received some objections from developers, regarding security of sites if multiple contractors are working at the same time. The developers of the SUEs have raised concerns that self-build plots may have a detrimental impact on their wider schemes in terms of varying designs and access complications. As argued by Wan, Shen and Yu [49], when a policy is perceived to be more effective, it is more likely to be actioned. Therefore, despite the objections, there is definite progress within the local authorities that were interviewed to consider the demand of the register when carrying out other functions. The majority perceive this to be working well, deeming the policy to be effective at achieving this outcome from the perspective of local authority planners. 
On the other hand, the interviewed developers emphasised that their experience, and the experience of other developers they have worked with, is that the local authorities are not doing enough when considering the demand of the register. They stated that the councils have no interest in taking the register into consideration when deciding planning applications, which is contrary to the point of the register. One developer expressed specific disappointment with this, as the main reason they started to pursue self and custom build schemes was because of the purpose of the register. However, they felt the purpose was being ignored and the local authorities were "making it as difficult as possible" to implement the schemes. Evidently, these experiences impact the perceived effectiveness of this objective. As participants' perceptions are partly based on their individual gains and losses [50], it is clear to see why the perceived effectiveness is much lower for developers due to their negative experiences.

\subsection{Addressing High Transaction Costs and Low Perceived Effectiveness of the Self-Build Registers}

\subsubsection{Reducing Transaction Costs}

The analysis of interviews indicated the key transaction costs occur when applicants face eligibility tests and registration fees. Throughout the interviews, both the local connection test and the registration fee were described as mechanisms to minimise the number of entries and suppress demand on the register. In line with Alexander [36], the tests and fee are exchanges of information and/or payment which results in increased transaction costs. Here, the transaction costs are heightened because the process is not efficient or equitable. For instance, the process might not be considered equitable as only $31 \%$ of councils impose some form of restriction. Consequently, one applicant may face complicated eligibility tests and a large fee to register for one authority, but an applicant registering for the neighboring authority may face nothing. The differing application processes across the national scale of the registers results in an inequitable process for applicants, dependent on which local authority they are applying to.

Furthermore, the eligibility tests and registration fees significantly increase the time and monetary costs to applicants who face them. As one developer stated, "the fees and local connection test that authorities have the discretion to apply are completely killing the sector dead, as they are stifling the real need". Consequently, it could be argued that certain authorities are purposely introducing additional transaction costs to the application process to limit the amount of people who apply and ensure every applicant is serious. In turn, this decreases the efficiency of the policy as the time taken to complete the tests and the monetary costs, with little return, can be seen as dead weight losses which decrease efficiency [42]. As a result, some the interviewed developers and NaCSBA representatives argued that the eligibility tests and fees should be removed from the register entirely as it is an unequal process, with very low value for money.

\subsubsection{Improving the Perceived Effectiveness}

According to the interviews, there are two main issues which are affecting the perceived effectiveness of the self-build register. Firstly, it was highlighted that applicants do not receive much support from the authority once they are added to the register. Secondly, developers and NaCSBA perceived the self-build register to be ineffective in terms of ensuring the council considers the demand on the register when carrying out their other functions.

Regarding the first issue, although local authorities are not legally required to offer support, it is significantly affecting the perceived effectiveness for all parties when nothing happens post application, which suggests this area of the policy should be improved. When interviewees were asked, "what more could be done to support people on the register?", several suggestions were given. Four local authority planners and two developers explored changing the structure of the register so it could facilitate direct communication between self and custom build developers and individuals on the register. This way, one of the developers highlighted, they could "submit plots and sites directly to people who are on 
the register". However, the data protection issues with this idea must be acknowledged, as it may be challenging for the local authority to share this information. Moreover, this is likely to work well for individuals who would like to 'custom build' with the help of a specialist developer but unlikely to assist the 'traditional DIY home', which is designed and built independently [18].

Another suggestion to develop the support given to individuals on the register was to provide connections and knowledge between those on the register and those working in the sector, through workshops. Whereby developers, planners, national bodies, and experienced individuals can all attend an event, which is facilitated by the authority, to share tips and advice. However, as mentioned previously, many authorities struggle to find the resources to deal with the register alone, meaning it is unlikely they would be able to provide this service. Upon further research, self and custom build workshops do take place, most notably the National Self Build and Renovation Centre in Swindon is a permanent centre designed to assist self-builders, renovators, and home improvers. The centre offers three-day courses for people considering a self-build project, at the price of $£ 395$. Therefore, to improve the support given to applicants and in turn improve the perceived effectiveness of the policy, all authorities should be made aware of existing workshops and centres so they can advise individuals where to look for the best advice if they cannot provide it. This could be achieved through a national list of available resources which is made publicly available. It should be noted that some authorities may already do this, but it was not mentioned by this sample, indicating a lack of awareness.

Secondly, as previously mentioned, the policy was deemed to be ineffective at ensuring the council considers the demand on the register when carrying out their other functions. A $\mathrm{NaCSBA}$ representative discussed that the absence of incentive for councils overperforming and penalty for councils underperforming has resulted in a mixed approach to this objective. Additionally, they highlight that is often down to the "fiscal persuasion of the council" to determine if they are using the register data to inform other planning functions. This should not be the case, as it allows some authorities to do the bare minimum when considering the demand on the register, deeming it ineffective. Three local authority planners highlighted the need for more government support and detail on implementing the policy, which could alleviate some of the inconsistencies in terms of how different local planning authorities respond to self-build. For instance, several authorities in coastal areas with very high demand have innovative Supplementary Planning Documents which identify the process in detail, they suggest a central government framework on how to develop this could be beneficial. Furthermore, a developer noted that the register should be more firmly embedded in national planning policy, arguing it "should be placed within the National Planning Policy Framework, rather than being tacked on in a separate piece of legislation". As Lubell, Mewhirter, Berardo and Scholz [50] highlights, perceptions can be formed around the policy's contribution to the collective good. Therefore, as the options suggested could work towards a more consistent approach to the self-build register across all authorities, it is likely to result in an increase in the perceived effectiveness of the objective, in terms of the collective good.

\section{Summary and Conclusions}

To address the housing crisis, the UK Government has adopted different strategies to increase the supply of housing and to diversify the housing market. Promoting and supporting self-build and custom housebuilding has been one of these strategies. The share of self-build and custom housebuilding from national housing completions in the UK has historically been very low, compared to most developed countries, and the UK Government has recently aimed to encourage these forms of house building by enacting the Self-build and Custom Housebuilding Act (2015). The Act has been a notable development in increasing these types of housing, particularly as it places a duty on local planning authorities to keep a statutory register of those within their respective administrative areas who wish to acquire a serviced plot of land and grant sufficient development permissions 
to meet the demand arising on the register. There has been very limited analysis of these policies thus far, particularly in terms of their associated transaction costs and their effectiveness in achieving objectives. The aim of this paper is to address this gap by evaluating the self-build register from the perspective of transaction costs and perceived effectiveness.

The paper firstly identified what transaction costs are associated with the application process to the self-build register and what parties they are incurred by. Broadly, the categories of activities were identified as applying to the register, eligibility tests, and post application. Overall, it can be concluded that applying to the register is a fairly straightforward process for the applicant and the local authority. However, each category of activities involves some form of transaction cost for the parties involved. For instance, the main barrier facing an applicant initial application is locating the form on the council's website, as they are not clearly publicised.

The analysis concluded that the largest transaction costs occur in the eligibility tests stage. As to become part of some registers, applicants are required to pass a local connection test and pay a registration fee. Passing the local connection test can require considerable time and effort from the applicant as they are required to prove beyond doubt that they have a connection to the area. Furthermore, registration fees are often extortionate compared to the service provided. Both pose significant barriers and costs to the applicant during the process.

Furthermore, uncertainty regarding the post application process also presents transaction costs for the applicant and the local authority. It is unclear to applicants what to expect once registered and they often expect more assistance than the local authority is legally required to provide. This results in uncertainty which increases transaction costs for the applicant. Whilst the local authority is required to spend time and human resources explaining that they have fulfilled their legal duties and do not need to assist further.

The paper also evaluated the perceived effectiveness of the self-build register, from the perspective of involved parties. The perceived effectiveness of policy instruments is measured through how well the policy is seen to be achieving the objectives it set out to achieve. The objectives of the self-build register were identified as aiming to increase the number of self and custom-build properties in England and ensuring the register is considered when councils carry out their functions relating to housing, planning, land disposal, and regeneration.

Objective one aims to increase the number of self and custom-build properties through raising awareness of the sector, measuring demand, and providing more support for people who want to build their own homes. This objective was determined through interview analysis and supporting government documents which clearly set out the intent to grow and support the sector. In terms of raising awareness, all interviewees concluded that the policy is effective, as the nationwide implementation has significantly increased the awareness. When measuring demand, the perceived effectiveness of the policy varies as some local authority planners think it provides a useful mechanism to measure. However, others question the validity, as applicants can apply to multiple registers resulting in distorted demand data. Finally, the policy is deemed to be ineffective at supporting people who want to build their own home, as local authorities are not legally required to provide any support, following the application. However, there is a common misconception among applicants that they will receive support, resulting in the policy being perceived as ineffective.

The second objective is concerned with how the self-build register data is used within each authority. As The Act states that councils must consider the demand on the selfbuild register when carrying out their other functions in relation to housing, planning, land disposal, and regeneration. The analysis concluded that there are major differences between how different parties perceive the effectiveness of the register regarding this objective. Local authority planners perceived the policy to be effective at achieving this objective, as the information is being utilised within the authority. Multiple examples were 
given of the data influencing Draft Local Plans and Planning Inspector policies. However, interviewed developers and NaCSBA representatives contended this as they stated the local authorities they had worked with for self and custom build projects had no interest in considering the register and appeared to make projects very difficult. These negative experiences have resulted in the policy being perceived as rather ineffective by developers and NaCSBA.

The research discussed how the eligibility tests and registration fee process can be modified to reduce transaction costs they produce. It concludes that the process is not equitable for applicants at a national scale, as some applicants will face high transaction costs regarding tests and fees but others, in different local authorities, will not encounter anything. Furthermore, it was determined that the process is not efficient. As there is limited support for applicants on the register, the time and monetary costs it takes to complete the eligibility test and pay large fees can be seen as dead weight losses, which decrease efficiency. As a result, the research recommends the policy should be amended to ensure it is consistent across all local authorities. Additionally, the eligibility tests should be removed as they prevent natural migration patterns within England.

In terms of perceived effectiveness, the key issues were identified as the lack of support from the local authority and councils not considering the demand of the register when carrying out their other functions. To provide more support for applicants, it was suggested that the policy was modified to facilitate direct communication between developers and individuals on the register and more information was provided through self and custom build workshops. Furthermore, to ensure the demand on the register is considered by all authorities, greater government support should be given to planning authorities through a central framework, which could use examples from successful coastal areas. Consequently, it is recommended that the policy is revised by central government to include a robust support system for individuals on the register, which could include forming connections with developers and/or experts. It is further recommended that guidance on how to successfully incorporate self and custom build into local planning is developed, this could be achieved through model Supplementary Planning Guidance documents or Local Plans.

Author Contributions: Conceptualization, G.S. and S.S.; investigation, G.S. and S.S.; writingoriginal draft preparation, G.S. and S.S.; writing-review and editing, G.S. and S.S.; supervision, S.S.; funding acquisition, S.S. All authors have read and agreed to the published version of the manuscript.

Funding: This research received no external funding.

Institutional Review Board Statement: The study was conducted according to the guidelines of the Declaration of Helsinki and the Ethics Committee of the School of Geography and Planning at Cardiff University.

Informed Consent Statement: Informed consent was obtained from all subjects involved in the study.

Data Availability Statement: Data sharing is not applicable to this article.

Conflicts of Interest: The authors declare no conflict of interest.

\section{References}

1. Gallent, N.; Durrant, D.; May, N. Housing supply, investment demand and money creation: A comment on the drivers of London's housing crisis. Urban Stud. 2017, 54, 2204-2216. [CrossRef]

2. Payne, S.; Serin, B.; James, G.; Adams, D. How Does the Land Supply System Affect the Business of UK Speculative Housebuilding? An Evidence Review; UK Collaborative Centre for Housing Evidence: Glasgow, UK, 2019.

3. Dickinson, D.; Shahab, S. Post Planning-Decision Process: Ensuring the Delivery of High-Quality Developments in Cardiff. Land Use Policy 2021, 100, 105114. [CrossRef]

4. Bramley, G. Housing market models and planning. Town Plan. Rev. 2013, 84, 9-35. [CrossRef]

5. Heffernan, E.; Wilde, P.D. Group self-build housing: A bottom-up approach to environmentally and socially sustainable housing. J. Clean. Prod. 2020, 243, 118657. [CrossRef]

6. DCLG. Right to Build: Supporting Custom and Self Build-Government Response to Consultation; Department for Communities and Local Government: London, UK, 2015. 
7. Barker, K. Review of Housing Supply. Delivering Stability: Securing Our Future Housing Needs. Available online: http: //news.bbc.co.uk/nol/shared/bsp/hi/pdfs/17_03_04_barker_review.pdf (accessed on 7 September 2020).

8. Archer, T.; Cole, I. Still not plannable? Housing supply and the changing structure of the housebuilding industry in the UK in 'austere' times. People Place Policy 2014, 8, 97-112. [CrossRef]

9. ONS. Average Household Income, UK. Available online: https://www.ons.gov.uk/peoplepopulationandcommunity/ personalandhouseholdfinances/incomeandwealth/bulletins/householddisposableincomeandinequality/financialyearending2 019 (accessed on 7 September 2020).

10. Barton, C.; Wilson, W. Tackling the Under-Supply of Housing in England; House of Commons Library: London, UK, 2020.

11. HBF. Reversing the Decline of Small Housebuilders: Reinvigorating Entrepreneurialism and Building More Homes. Available online: https://www.hbf.co.uk/documents/6879/HBF_SME_Report_2017_Web.pdf (accessed on 7 September 2020).

12. Archer, T.; Cole, I. Profits before Volume?: Major Housebuilders and the Crisis of Housing Supply; Sheffield Hallam University: Sheffield, UK, 2016.

13. Letwin, O. Independent Review of Build Out; Ministry of Housing, Communities and Local Government: London, UK, 2018.

14. Duncan, S.S.; Rowe, A. Self-provided Housing: The First World's Hidden Housing Arm. Urban Stud. 1993, 30, 1331-1354. [CrossRef]

15. Benson, M.; Hamiduddin, I. Self-Build Homes: Social Discourse, Experiences and Directions; University College London: London, UK, 2017.

16. Gingell, A.H.; Shahab, S. An Analysis of Self-Build and Custom Housebuilding in the South West of England. Urban Sci. 2021, 5, 9. [CrossRef]

17. NaCSBA. An Action Plan to Promote the Growth of Self-Build Housing; National Custom and Self-build Association: Cheltenham, UK, 2011.

18. Wilson, W. Self-Build and Custom Build Housing (England); House of Commons Library: London, UK, 2017.

19. Shahab, S.; Clinch, J.P.; O'Neill, E. Accounting for Transaction Costs in Planning Policy Evaluation. Land Use Policy 2018, 70, 263-272. [CrossRef]

20. Hou, J.; Gu, D.; Shahab, S.; Chan, E.H.-w. Implementation analysis of transfer of development rights for conserving privately owned built heritage in Hong Kong: A transactions costs perspective. Growth Chang. 2020, 51, 530-550. [CrossRef]

21. Derkacz, A.J.; Shahab, S. Społeczno-Gospodarcza Aktywność Człowieka Kontraktującego w Ujęciu Nowej Ekonomii Instytucjonalnej; Wydawnictwo Społecznej Akademii Nauk: Łódź, Poland, 2020. [CrossRef]

22. Bennett, N.J. Using perceptions as evidence to improve conservation and environmental management. Conserv. Biol. J. Soc. Conserv. Biol. 2016, 30, 582-592. [CrossRef]

23. Benson, M. Creating a Nation of Selfbuilders. An Interim Report from the Project Selfbuilding: The Production and Consumption of New Homes from the Perspective of Households; Department of Sociology, Goldsmith: London, UK, 2014.

24. Parvin, A.; Saxby, D.; Cerulli, C.; Schneider, T. A Right to Build the Next Mass-Housebuilding Industry; University of Sheffield: Sheffield, UK, 2011.

25. Wallace, A.; Ford, J.; Quilgars, D. Build-It-Yourself? Understanding the Changing Landscape of the UK Self-Build Market; Centre for Housing Policy, University of York: York, UK, 2013.

26. Ash, C.; Birbeck, D.; Brown, S.; Cerulli, C.; Stevenson, F. Motivating Collective Custom Build Report; University of Sheffield: Sheffield, UK, 2013.

27. NaCSBA. NaCSBA Research Highlights Unequal Picture of Right to Build Registers in England. Available online: https: // nacsba.org.uk/news/nacsba-maps-of-right-to-build-registers (accessed on 7 November 2019).

28. MHCLG. Self-Build and Custom Housebuilding. Available online: https://www.gov.uk/guidance/self-build-and-customhousebuilding (accessed on 22 November 2019).

29. NaCSBA. Right to Build Freedom of Information Request Analysis of Local Authority Activity around the Right to Build Registers; National Custom and Self-Build Association: London, UK, 2020.

30. Laurian, L.; Crawford, J.; Day, M.; Kouwenhoven, P.; Mason, G.; Ericksen, N.; Beattie, L. Evaluating the outcomes of plans: Theory, practice, and methodology. Environ. Plan. B Plan. Des. 2010, 37, 740-757. [CrossRef]

31. Shahab, S.; Clinch, J.P.; O’Neill, E. Impact-based planning evaluation: Advancing normative criteria for policy analysis. Environ. Plan. B Urban Anal. City Sci. 2019, 46, 534-550. [CrossRef]

32. Shahab, S.; Clinch, J.P.; O'Neill, E. An Analysis of the Factors Influencing Transaction Costs in Transferable Development Rights Programmes. Ecol. Econ. 2019, 156, 409-419. [CrossRef]

33. Coase, R.H. The Nature of the Firm. Economica 1937, 4, 386-405. [CrossRef]

34. Alexander, E.R. A Transaction Cost Theory of Planning. J. Am. Plan. Assoc. 1992, 58, 190-200. [CrossRef]

35. Williamson, O.E. Transaction Cost Economics: How It Works; Where It is Headed. Economist 1998, 146, 23-58. [CrossRef]

36. Alexander, E.R. A Transaction-Cost Theory of Land Use Planning and Development Control: Towards the Institutional Analysis of Public Planning. Town Plan. Rev. 2001, 72, 45-75. [CrossRef]

37. Williamson, O.E. The Economic Institutions of Capitalism; Free Press: New York, NY, USA, 1985.

38. Shahab, S.; Viallon, F.-X. A transaction-cost analysis of Swiss land improvement syndicates. Town Plan. Rev. 2019, 90, 545-565. [CrossRef] 
39. Cho, C.-J. An Analysis of the Housing Redevelopment Process in Korea through the Lens of the Transaction Cost Framework. Urban Stud. 2011, 48, 1477-1501. [CrossRef]

40. McCann, L.; Colby, B.; Easter, K.W.; Kasterine, A.; Kuperan, K.V. Transaction Cost Measurement for Evaluating Environmental Policies. Ecol. Econ. 2005, 52, 527-542. [CrossRef]

41. Buitelaar, E. The Cost of Land Use Decisions: Applying Transaction Cost Economics to Planning and Development; Blackwell Publishing: Oxford, UK, 2007.

42. Buitelaar, E. A Transaction-cost Analysis of the Land Development Process. Urban Stud. 2004, 41, 2539-2553. [CrossRef]

43. Shahab, S.; Lades, L.K. Sludge and Transaction Costs; Ucd Geary Institute for Public Policy: Dublin, Ireland, 2020.

44. Shahab, S.; Clinch, J.P.; O'Neill, E. Estimates of Transaction Costs in Transfer of Development Rights Programs. J. Am. Plan. Assoc. 2018, 84, 61-75. [CrossRef]

45. Sadler, B. International Study of the Effectiveness of Environmental Assessment; International Association for Impact Assessment and Canadian Environmental Assessment Agency, Ministry of Supply and Services: Ottawa, ON, Canada, 1996.

46. Hartmann, T.; Spit, T. Dilemmas of involvement in land management-Comparing an active (Dutch) and a passive (German) approach. Land Use Policy 2015, 42, 729-737. [CrossRef]

47. Morrison, N.; Pearce, B. Developing Indicators for Evaluating the Effectiveness of the UK Land Use Planning System. Town Plan. Rev. 2000, 71, 191-211. [CrossRef]

48. Wan, C.; Shen, G.Q.; Yu, A. The role of perceived effectiveness of policy measures in predicting recycling behaviour in Hong Kong. Resour. Conserv. Recycl. 2014, 83, 141-151. [CrossRef]

49. Wan, C.; Shen, G.Q.; Yu, A. The moderating effect of perceived policy effectiveness on recycling intention. J. Environ. Psychol. 2014, 37, 55-60. [CrossRef]

50. Lubell, M.; Mewhirter, J.M.; Berardo, R.; Scholz, J.T. Transaction Costs and the Perceived Effectiveness of Complex Institutional Systems. Public Adm. Rev. 2017, 77, 668-680. [CrossRef]

51. Greiner, R.; Gregg, D. Farmers' intrinsic motivations, barriers to the adoption of conservation practices and effectiveness of policy instruments: Empirical evidence from northern Australia. Land Use Policy 2011, 28, 257-265. [CrossRef]

52. Galletta, A. Mastering the Semi-Structured Interview and Beyond: From Research Design to Analysis and Publication; NYU Press: New York, NY, USA, 2013.

53. Guest, G.; Bunce, A.; Johnson, L. How Many Interviews Are Enough? Field Methods 2006, 18, 59-82. [CrossRef]

54. Guion, L.A.; Diehl, D.C.; McDonald, D. Conducting an in-Depth Interview; Institute of Food and Agricultural Sciences, University of Florida Cooperative Extension Service: Gainesville, FL, USA, 2001.

55. Nowell, L.S.; Norris, J.M.; White, D.E.; Moules, N.J. Thematic Analysis: Striving to Meet the Trustworthiness Criteria. Int. J. Qual. Methods 2017, 16. [CrossRef]

56. Alexander, E.R. Governance and Transaction Costs in Planning Systems: A Conceptual Framework for Institutional Analysis of Land-Use Planning and Development Control-The Case of Israel. Environ. Plan. B Plan. Des. 2001, 28, 755-776. [CrossRef] 